\title{
ESTRATÉGIAS DE ESCRITA PARA ABORDAGEM DA COMUNICAÇÃo PÚBLICA DA CIÊNCIA NA EDUCAÇÃo EM QUÍMICA
}

\author{
Carolina Sotério $^{\text {a }}$ Salete Linhares Queiroz ${ }^{*, a,}$, \\ anstituto de Química de São Carlos, Universidade de São Paulo, 13560-970, São Carlos - SP, Brasil
}

Recebido em 11/04/2020; aceito em 11/05/2020; publicado na web em 30/06/2020

\begin{abstract}
WRITING STRATEGIES FOR INCORPORATING PUBLIC COMMUNICATION OF SCIENCE INTO CHEMISTRY EDUCATION. Although the impacts of science discoveries are relevant to society, awareness of this intellectual output is still minimal. Much of this communicative failure between researchers and the general public lies in the disclosure, which contributes to the superficiality and misinterpretations of the content served. Strategies need to be found to improve science communication worldwide, promoting well-grounded content and accessible language to a non-specialist audience. This work aims to report writing strategies used in a course about public communication of science, offered to undergraduate chemistry students. The results showed that students fully achieved the task of writing popular science texts as a science journalist, emphasizing their ease and difficulties throughout the activity.
\end{abstract}

Keywords: public communication of science; science popular texts; science writing; chemistry; higher education.

\section{INTRODUÇÃO}

O desenvolvimento da ciência e suas implicações tecnológicas estão vinculados à existência humana ao longo do tempo. Diversas descobertas científicas foram de fundamental relevância para mudanças avassaladoras em nosso cotidiano, entre elas a Internet, os medicamentos, a automobilística e a exploração do espaço. No entanto, apesar de ser possível constatar diariamente avanços nos estudos de ciências básicas e aplicadas, grande parte da população não tem conhecimento de toda essa produção intelectual.

Cabe destacar que essa problemática é antecedida por uma comunicação deficitária entre a Ciência e Tecnologia e a Sociedade. ${ }^{1}$ Muito dessa falha comunicativa entre os pesquisadores e o público em geral, essencial para que haja conscientização da necessidade do investimento em pesquisa em prol do desenvolvimento da nação, está na divulgação realizada. Muitas vezes o autor do texto de divulgação científica (TDC) se coloca no papel de um padre que transmite uma mensagem divina e de autoridade a uma congregação. Faz-se então necessário que essa relação de sacerdócio se quebre e uma das formas para que isso ocorra é com o desenvolvimento de habilidades, por parte de pesquisadores, de comunicar à imprensa um conteúdo detalhado e de linguagem acessível sobre os seus respectivos estudos. ${ }^{2}$

Em uma comparação evolutiva da divulgação científica, sua reportagem surgiu de uma Era Gee-Whiz, em que a divulgação das grandes descobertas baseava-se somente em enaltecer as maravilhas da ciência; passou pela Era Watchdog, quando os escritores científicos tornaram-se mais críticos após episódios como o lançamento das bombas atômicas, até o que hoje é chamada de Era Digital. Mesmo nessa Era mais recente, a dedicação da mídia à ciência é muito menor em comparação a áreas como entretenimento, política, esportes ou negócios. ${ }^{3}$ Isso se deve à dificuldade que muitos autores encontram em escrever sobre ciência, uma vez que essa prática requer um considerável leque de informações e são raros os que possuem formação na área. ${ }^{4}$ Ainda assim, no contexto nacional, algumas revistas fazem uma abordagem científica rica e sofisticada para um público amplo, como a Ciência Hoje e a Revista Pesquisa FAPESP.

*e-mail: salete@iqsc.usp.br
Debates sobre o investimento de verbas públicas em pesquisa e desenvolvimento têm sido assíduos em uma época de crise. Universidades de grande porte como o Massachusetts Institute of Technology (MIT) cobrem 67\% de suas despesas anuais com pesquisa com verba pública, ${ }^{5}$ o que provavelmente contribui para que seja considerada uma das melhores do mundo. ${ }^{6}$ Dito isso, é preciso que se faça entender que investimento científico é intrinsecamente necessário para o desenvolvimento de novas tecnologias e resolução de problemas críticos da sociedade. Ademais, mediante os resultados de alta qualidade que algumas universidades apresentam em suas pesquisas, o investimento em sua manutenção não é caro, uma vez que prejuízo é não produzir nenhuma tecnologia, e por isso a comunicação pública de ciência (CPC) tem o papel essencial de conscientizar a população sobre tal importância. ${ }^{5}$ Ainda, o investimento em divulgação das atividades de pesquisa pode culminar na escolha de carreiras científicas por jovens que antes não a considerariam como uma alternativa real de profissão. ${ }^{7}$

A CPC efetiva, por sua vez, é capaz de contribuir para a formação de um cidadão consciente de suas escolhas em sociedade, que diferencia informações científicas confiáveis de informações pseudocientíficas. ${ }^{8}$ Nessa perspectiva, é válido ressaltar o quanto saber comunicar ciência a um público amplo é relevante para a formação de graduandos em química. De fato, segundo as Diretrizes Curriculares para os Cursos de Química, o estudante deve ter acesso a uma formação técnica e humanística, além de "ter consciência da importância social da profissão como possibilidade de desenvolvimento social e coletivo" (p. 457) e "ter capacidade de disseminar e difundir e/ ou utilizar o conhecimento relevante para a comunidade" (p. 457). ${ }^{9}$ Dessa forma, a atenção dispensada ao desenvolvimento da CPC pelos graduandos favorece a constituição de um profissional consciente para analisar tanto o conteúdo científico ao qual tem acesso quanto aquele que, eventualmente, venha a produzir.

É nesse contexto que se tornam recorrentes relatos na literatura sobre o desenvolvimento de ações visando a abordagem da CPC em cursos de graduação em ciências da natureza, a partir da inserção de estratégias de escrita científica, leitura crítica de informações científicas e identificação de fontes confiáveis. ${ }^{8}$ De fato, inclusive essa Revista conta com artigo de revisão que destaca a relevância de tais ações. ${ }^{10}$ 
Tendo em vista o exposto, o presente trabalho tem como objetivo relatar o desenvolvimento de um curso de CPC voltado para estudantes de graduação em química, investigar os seus conhecimentos a respeito dos veículos de divulgação científica, bem como aqueles que mobilizaram para a produção final do curso, um TDC de tema livre. Pretende-se, dessa forma, contribuir para a ampliação de iniciativas dessa natureza no ensino de química.

\section{CONTEXTO DE DESENVOLVIMENTO DO CURSO DE COMUNICAÇÃO PÚBLICA DE CIÊNCIA}

O curso em questão, gratuito, com duração de dez horas, foi realizado na sala de informática do Centro de Divulgação Científica e Cultural da Universidade de São Paulo (CDCC/USP), voltado a estudantes membros ou colaboradores do grupo de extensão universitária American Chemical Society Student Chapter do Curso de Bacharelado em Química do Instituto de Química de São Carlos da Universidade de São Paulo (IQSC/USP), contou com seis participantes (33,3\% do sexo feminino e $67,7 \%$ masculino) e foi ministrado pela primeira autora do presente manuscrito. Os temas tratados buscaram o favorecimento e fomento à discussão sobre as formas de CPC, com enfoque em TDC, e os elementos que os caracterizam.

O curso teve como conteúdo programático: TDC com foco em critérios para redação e análise; CPC: breve panorama histórico, implicações sociais, veículos nacionais e internacionais e; Elaboração de TDC, subsidiado por dinâmicas de equipe pautadas nos princípios de aprendizagem cooperativa (AC). ${ }^{11,12}$ Esta constitui-se em metodologia de ensino baseada na formação de pequenos grupos de alunos, de modo que, para que todo o grupo alcance seus objetivos, é necessário que cada membro desempenhe um papel específico.

As características essenciais da AC foram integradas às etapas de desenvolvimento do curso de CPC, sendo elas: interação social face-a-face, que se refere à interação e comunicação entre os estudantes para que trabalhem juntos e ofereçam suporte uns aos outros; interdependência positiva, que remete ao trabalho em equipe com o propósito de atingir um objetivo em comum, de forma a perceberem que a performance de cada um beneficia a todos; responsabilidade individual, que atribui a cada integrante do grupo uma função específica para que a atividade seja bem-sucedida; habilidades interpessoais e de grupo, que se referem à observação e alcance das habilidades sociais desenvolvidas durante toda a atividade proposta, tais como liderança e resolução de conflitos; processamento grupal, que consiste no levantamento de críticas construtivas pelos membros do grupo a respeito de suas contribuições para o êxito da atividade.

Os recursos utilizados pelos alunos abrangiam crachás e $Q R$ Codes, assim como plataformas online, site de edição de imagem Canva e slides. Para questões realizadas com expectativa de respostas anônimas, foi utilizado o aplicativo Plicker, o qual consiste em $Q R$ Codes com até quatro alternativas (A, B, C e D), cuja leitura e contabilização das respostas são realizadas por meio da câmera de celular de forma instantânea. ${ }^{13}$ Também foram utilizados questionários elaborados na plataforma Google Forms para coleta de dados instantânea, além da plataforma Google Drive para compartilhamento de arquivos como formulários, TDC da Revista Pesquisa FAPESP, apostila de curso e material produzido pelos participantes.

\section{ELEMENTOS DE TEXTOS DE DIVULGAÇÃO CIENTÍFICA ABORDADOS NO CURSO}

Os conteúdos programáticos mencionados anteriormente, “TDC com foco em critérios para redação e análise" e "Elaboração de TDC", foram abordados com base nos elementos presentes no Quadro Analítico ${ }^{14}$ descrito na sequência.

\section{Quadro de Análise de TDC ${ }^{14}$}

Ferreira e Queiroz, ${ }^{14}$ em Quadro Analítico publicado nesta Revista (Figura 1), sugerem a investigação de TDC com base nas perspectivas de conteúdo e forma dos textos. Embora o Quadro tenha sido originalmente empregado como meio para explorar o potencial didático dos TDC por professores no ensino de ciências, no contexto do presente trabalho funcionou como instrumento didático para apresentação de elementos existentes no TDC aos graduandos matriculados no curso de CPC.

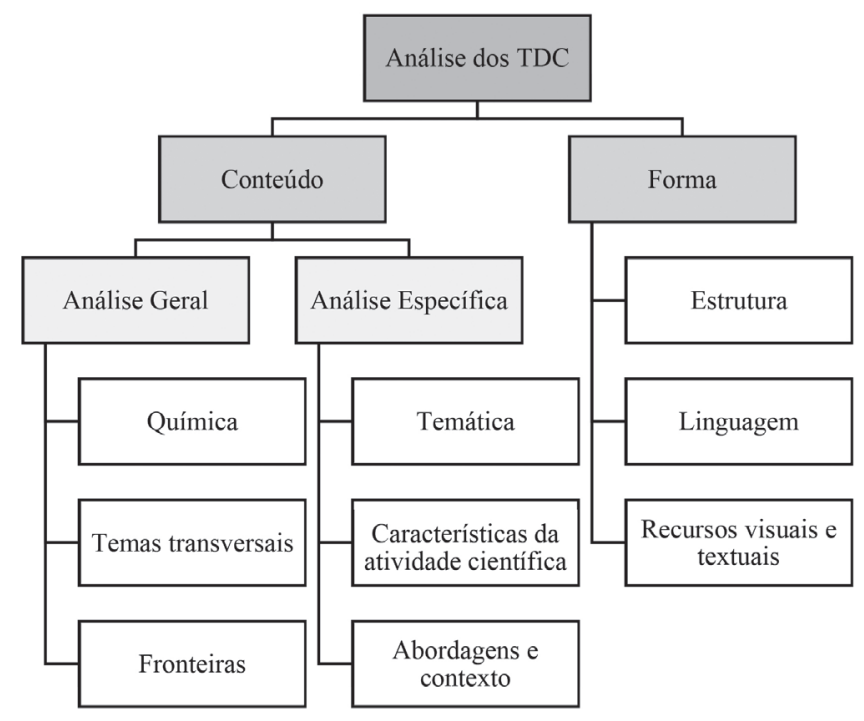

Figura 1. Quadro Analítico para a investigação de $T D C^{14}$

No Quadro Analítico, ${ }^{14}$ o conteúdo pode ser associado, de forma geral, a três subcategorias: química, temas transversais e fronteiras. A primeira categoria se refere ao conteúdo considerado formal de química, comumente ministrado nos anos de ensino escolar. Os temas transversais, por sua vez, referem-se ao conteúdo presente na Base Nacional Comum Curricular (BNCC) $)^{15}$ que não é intrínseco a uma disciplina, mas é abordado em muitas delas, como os valores de cidadania. Já na subcategoria de fronteiras estão aqueles que não são tradicionalmente abordados no ensino formal de química, mas que se relacionam com ele, tal como a física. Em uma análise específica do conteúdo, faz-se possível observar a temática, as características da atividade científica e as abordagens e contexto.

A subcategoria temática abarca o enfoque do TDC, enquanto que a referente às características da atividade científica inclui partes do texto que corroboram com a prática científica, tais como descrições de metodologias, trabalhos em equipe, análise de dados, interpretação de resultados, controvérsias científicas, quebra de paradigmas, entre muitos outros. Por último, a subcategoria abordagens e contexto traz o meio no qual o texto está inserido, seja este social, político, econômico, entre outros.

No que diz respeito à forma dos TDC, a análise ocorre em relação à estrutura, linguagem e recursos visuais e textuais. A primeira subcategoria refere-se, por exemplo, à fragmentação do texto, em pequena ou grande proporção. Em relação à linguagem, pode-se identificar o uso de comparações, analogias e metáforas, por exemplo. Em recursos visuais e textuais estão a distribuição espacial das informações, uso de caixas de texto, imagens relacionadas com o tema, títulos destacados de forma atrativa, entre outros.

Para o estudo de TDC pelos graduandos, uma ficha de análise de conteúdo e forma foi empregada, cuja formulação se deu a partir do Quadro Analítico. ${ }^{14}$ 


\section{ETAPAS DE DESENVOLVIMENTO DO CURSO DE COMUNICAÇÃO PÚBLICA DE CIÊNCIA}

O curso de comunicação científica (CC) foi realizado em dois dias consecutivos, em cinco etapas, indicadas como Parte I e II, respectivamente, conforme ilustra a Figura 2. Na Parte I, foram contempladas as etapas de 1 a 4, com duração de seis horas. A Parte II, por sua vez, contemplou a etapa 5 , com duração de quatro horas. Cada uma das etapas é descrita a seguir.

\section{Etapa 1: Aula teórica}

A primeira etapa demandou duas horas para realização. Aplicouse, inicialmente, um questionário de conhecimentos prévios com a indagação "O que você entende por comunicação pública de ciência?", cujas respostas foram registradas na plataforma Google Forms. Na sequência, houve exibição do vídeo intitulado "A importância da Comunicação Científica", de autoria da primeira autora deste manuscrito, baseado em entrevistas com estudantes de graduação em química e ciência da computação da USP, campus de São Carlos, sobre a dificuldade de compreensão de trabalhos descritos em currículos de professores da instituição. O propósito da exibição foi promover uma discussão do assunto, fazendo assim a introdução sobre a importância da CPC, baseada em trabalhos publicados no âmbito da temática. ${ }^{2,3}$

A aula expositiva dialogada contou com o levantamento de enquetes. Por exemplo, quando na discussão sobre mídias que veiculam TDC, o aplicativo Plicker foi utilizado para coletar dados da pergunta anônima Qual das alternativas abaixo é um veículo de divulgação científica?, exposta em um slide com alternativas. Foram registradas as respostas e fez-se uma discussão sobre estas, sendo introduzidos, assim, alguns veículos nacionais e internacionais de CPC, com enfoque nas revistas que publicam TDC. Em seguida, aplicou-se a questão Com quais desses veículos de divulgação científica você já teve contato?, que também dispunha de uma série de opções. Após a coleta de respostas, foram apresentados os elementos característicos de um TDC. Essa apresentação pautou-se em informações presentes em $\operatorname{artigos}^{4,14}$ e livro ${ }^{16}$ sobre o assunto.

\section{Etapa 2: Análise de TDC da Revista Pesquisa FAPESP}

$\mathrm{Na}$ segunda etapa, realizada em duas horas, foi iniciada uma



Figura 2. Etapas e descrição dos tópicos ministrados no curso de CPC simulação da redação de uma revista de divulgação científica em processo de elaboração de um material de edição única. Os estudantes assumiram o papel de jornalistas e, inicialmente, necessitavam ler, discutir e analisar um TDC recebido pela redação, que seria posteriormente apresentado à editora (papel atribuído à ministrante do curso). O TDC em questão foi "A luz que enxerga o que não viu", originalmente publicado pela Revista Pesquisa FAPESP. ${ }^{17}$

$\mathrm{O}$ TDC trata de um fenômeno que trouxe à tona as estranhezas da mecânica quântica: a obtenção de imagens de objetos sem que os fótons (as partículas elementares da luz) tenham entrado em contato direto com eles. ${ }^{17} \mathrm{~A}$ escolha do texto baseou-se na sua extensão, adequada às dinâmicas de leitura do curso, e também nos elementos nele presentes, destacando-se a disposição de um título atrativo, linguagem acessível, imagem chamativa vinculada ao conteúdo e publicação em veículo de ampla circulação.

Baseado nos elementos essenciais da $\mathrm{AC},{ }^{11,12}$ explicitados antes do início da simulação, foram fornecidas instruções sobre a dinâmica dessa etapa: os jornalistas foram divididos em três duplas, sendo que em cada uma delas havia um membro com o papel de leitor e o outro de redator, identificados pelo uso de crachás. Foi proposto que, em um primeiro momento, as duplas executassem a leitura e análise do texto e se preparassem para uma apresentação oral posterior do mesmo para toda a plateia, que nesse caso representava a equipe de redação da revista, incluindo a editora, dedicando 50 minutos para isso.

O leitor era o jornalista de ciência responsável pela leitura em voz alta do TDC recebido e elaboração de um pôster que subsidiasse a apresentação oral da análise feita sobre o TDC. O redator era o jornalista de ciência responsável por preencher e apresentar oralmente uma ficha de análise de conteúdo e forma do TDC, que contempla os elementos que comumente compõem esse tipo textual e que haviam sido discutidos na Etapa 1. A ficha foi disponibilizada via Google Drive. Era permitida a discussão do TDC entre os integrantes de cada dupla durante todo o período da simulação. A esquematização da dinâmica consta na Figura 3.

O processo culminou quando os leitores realizaram a apresentação oral, que ocupou o restante do tempo da etapa em questão. Para tanto, os pôsteres foram elaborados a partir da utilização das ferramentas gratuitas do site Canva e apresentados com auxílio de projetor de slides.

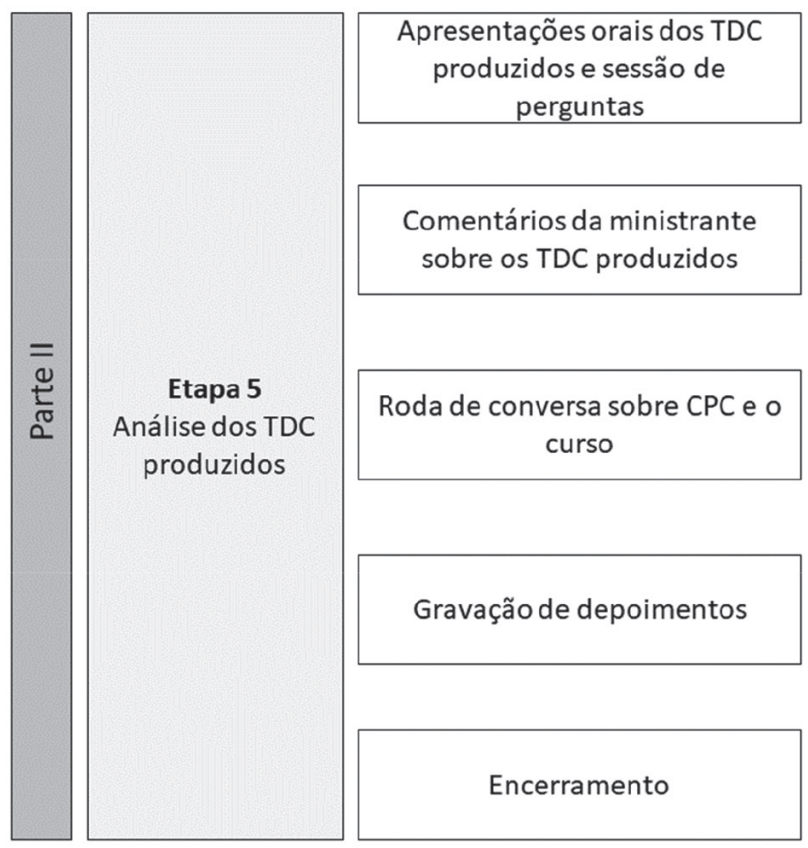



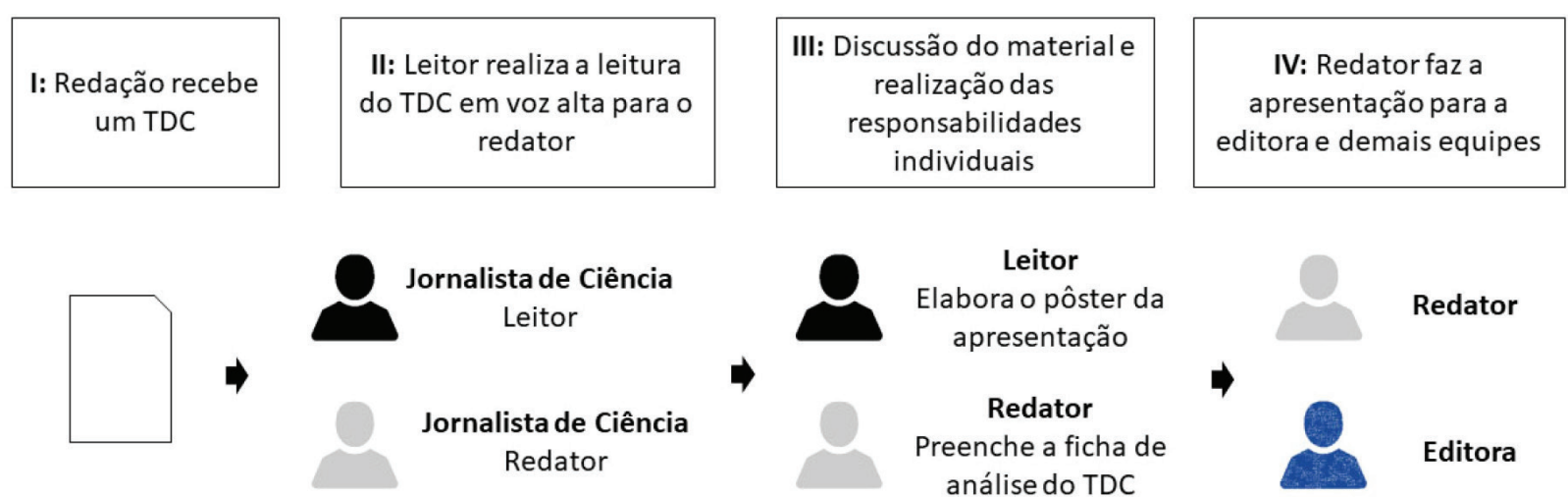

Figura 3. Simulação da redação de uma revista de divulgação científica na etapa de leitura, discussão e análise de um TDC recebido, pautada em AC

\section{Etapa 3: Discussão da análise do TDC}

Na terceira etapa, com duração de quinze minutos, a editora fez comentários pertinentes às apresentações, mostrando os elementos que eram esperados de serem identificados no TDC trabalhado, com base na referida ficha de análise de conteúdo e forma de TDC, esquematizada na Figura 4.

Na ocasião, a editora também mostrou uma análise ideal do TDC em questão, conforme Figura 5. Após apresentação dos elementos esperados de serem identificados no TDC, os participantes discutiram sobre os mesmos e compararam com os que haviam apresentado nas suas respectivas fichas.

\section{Etapa 4: Produção de TDC pelos participantes}

Após a etapa anterior, que cuidou de esclarecer os elementos presentes em um TDC e os critérios para analisá-los, a quarta etapa exigiu a produção de um TDC por cada um dos participantes, com tempo de atividade de uma hora e 45 minutos. A dinâmica retomou a situação em que cada um dos estudantes seria um jornalista científico, porém agora no processo de redação do próprio TDC. Sendo assim, cada um deles teve acesso ao site da Revista Pesquisa FAPESP para que pesquisassem textos e investigações realizadas a respeito de assunto sobre o qual gostariam de escrever.

Inicialmente, os jornalistas escolheram a área de interesse de sua pauta e escreveram em uma folha de papel, anexando-a em sua mesa de redação para que nenhum outro colega tratasse da mesma temática. A redação individual dos TDC baseou-se no processo de peer-review, ${ }^{18}$ no qual os estudantes começavam a escrever seus textos e, por duas vezes, eram interrompidos por seus colegas para o processo de revisão. Isso é, de forma aleatória, os jornalistas pausavam o processo de escrita de seus textos para ler o texto de outro colega e fazer comentários e revisões, garantindo que cada integrante não revisasse duas vezes o mesmo TDC. Para isso, em um primeiro momento os jornalistas das equipes da dinâmica anterior (Figura 3) atuaram como pareceristas entre si e, em um segundo instante, um jornalista com o qual ainda não se tivesse trabalhado. Após cada revisão, eles voltavam aos seus textos originais para acatar os comentários e finalizá-los, até que estes fosses enviados, por fim, para análise da editora do jornal. Na Figura 6 consta a esquematização da dinâmica.

No âmbito da ciência, o processo de peer-review se dá, usualmente, pela escolha de árbitros que avaliarão a qualidade de artigos submetidos para publicação em revistas com seletiva política editorial. Os árbitros devem se encontrar na subespecialidade mais próxima possível do trabalho a ser avaliado, de forma a garantir que os procedimentos descritos no texto estejam corretos tanto quanto for possível. O julgamento do trabalho em si é realizado com base em critérios determinados pela comunidade científica. ${ }^{16}$ No âmbito do ensino, o peer-review pode revelar um indicador das habilidades

\begin{tabular}{|c|c|c|}
\hline \multicolumn{3}{|c|}{ Ficha de Análise de Conteúdo e Forma de TDC } \\
\hline \multicolumn{3}{|c|}{ Análise Geral do Conteúdo } \\
\hline Química & Fronteiras & Transversais \\
\hline \multicolumn{3}{|c|}{ Descrição do Conteúdo } \\
\hline \multicolumn{3}{|c|}{$\ldots$} \\
\hline \multicolumn{3}{|c|}{ Análise Específica do Conteúdo } \\
\hline Temática & Características da atividade científica & Abordagens e contexto \\
\hline \multicolumn{3}{|c|}{ Forma } \\
\hline Estrutura & Linguagem & Recursos visuais e textuais \\
\hline \multicolumn{3}{|c|}{ Principais conclusões } \\
\hline & $\cdots$ & \\
\hline
\end{tabular}

Figura 4. Esquematização resumida da ficha de análise de conteúdo e forma de TDC ${ }^{14}$ 
Ficha de Análise de Conteúdo e Forma do TDC "A luz que enxerga o que não viu" (Pesquisa FAPESP)

\begin{tabular}{|c|c|c|}
\hline \multicolumn{3}{|c|}{ Análise Geral do Conteúdo } \\
\hline Química & Fronteiras & Transversais \\
\hline \multicolumn{3}{|c|}{ Descrição do Conteúdo } \\
\hline \multicolumn{3}{|c|}{ Física. Grandes áreas: óptica, mecânica quântica } \\
\hline \multicolumn{3}{|c|}{ Análise Específica do Conteúdo } \\
\hline $\begin{array}{l}\text { Temática } \\
\text { O enfoque do texto se dá aos } \\
\text { fenômenos quânticos que permitiram a } \\
\text { captura de uma imagem sem que os } \\
\text { fótons estabelecessem um contato } \\
\text { direto com o objeto }\end{array}$ & $\begin{array}{c}\text { Características da atividade científica } \\
\text { Experimento do gato de Schrödinger, } \\
\text { métodos e equipamentos, } \\
\text { interpretação de resultados, conclusão, } \\
\text { característica pessoal, quebra de } \\
\text { paradigmas, patente, referência, } \\
\text { trabalho em equipe, aspecto histórico, } \\
\text { hipótese, dificuldades }\end{array}$ & $\begin{array}{l}\text { Abordagens e contexto } \\
\text { Científica e conceitual }\end{array}$ \\
\hline \multicolumn{3}{|c|}{ Forma } \\
\hline $\begin{array}{c}\text { Estrutura } \\
\text { Sequência lógica. Ausência de } \\
\text { fragmentação }\end{array}$ & $\begin{array}{c}\text { Linguagem } \\
\text { Presença de procedimentos } \\
\text { explicativos, definição por } \\
\text { conceituação (fóton), aspas, apelo à } \\
\text { atenção (título chamativo), } \\
\text { credibilidade (cita Schrödinger, o } \\
\text { professor, a universidade), metáforas } \\
\text { (O bruxo de Viena), inserção de falas de } \\
\text { especialistas }\end{array}$ & $\begin{array}{l}\text { Recursos visuais e textuais } \\
\text { llustração alusiva ao tema (imagem do } \\
\text { gato) e título impactante }\end{array}$ \\
\hline \multicolumn{3}{|c|}{ Principais conclusões } \\
\hline
\end{tabular}

Figura 5. Esquematização resumida da ficha de análise de conteúdo e forma de $T D C^{13}$ preenchida para o texto "A luz que enxerga o que não viu”"17

\begin{tabular}{|l|}
\hline I: Definição das \\
pautas e início \\
da redação do \\
TDC
\end{tabular}

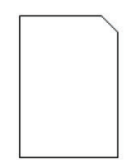

II a. Primeiro peer-review com jornalista da própria equipe

II b. Retorno à escrita do TDC original

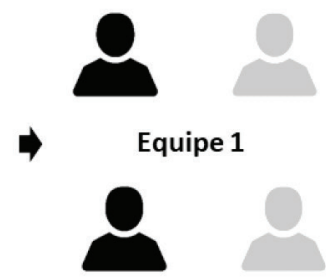

Equipe 2
III a. Segundo peer-review com jornalista de outra equipe

III b. Retorno à escrita e

finalização do TDC original

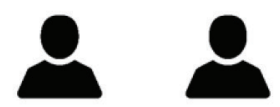

Equipe 1



Equipe 2
IV: Entrega do TDC finalizado à editora
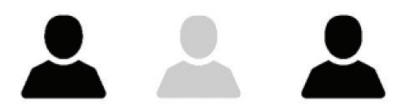

Jornalistas

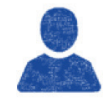

Editora

Figura 6. Simulação da redação de uma revista de ciência na etapa de produção de um TDC, pautada em AC

dos estudantes nesse processo de revisão dos trabalhos dos colegas, mediante o estabelecimento e clareza dos critérios de análise, julgamento e feedback da produção textual. ${ }^{18}$

Nos últimos dez minutos, realizou-se o processamento grupal, momento no qual os participantes escreveram críticas construtivas sobre o papel dos colegas nas dinâmicas do curso. Foram utilizados arquivos com o nome de cada integrante, previamente disponíveis no Google Drive, para que os estudantes registrassem seus comentários construtivos a respeito das contribuições de cada um ao longo do curso. O objetivo, tanto das etapas de edição quanto da de redação, era o de subsidiar o entendimento dos elementos que compõem os
TDC, a fim de elaborar uma suposta revista de edição única com TDC originalmente escritos pelos participantes do curso.

\section{Etapa 5: Análise dos TDC produzidos}

Por fim, na quinta e última etapa, com duração de quatro horas, os jornalistas fizeram a comunicação oral do conteúdo do TDC produzido na etapa 4, no formato de pôster. Além da apresentação em si, cada jornalista elaborou uma questão-chave sobre o conteúdo de seu TDC. Após cada apresentação, a questão-chave era lida pelo seu autor e respondida pelos colegas de redação utilizando o aplicativo Plicker, conforme ilustra a Figura 7. O resultado dos acertos era 


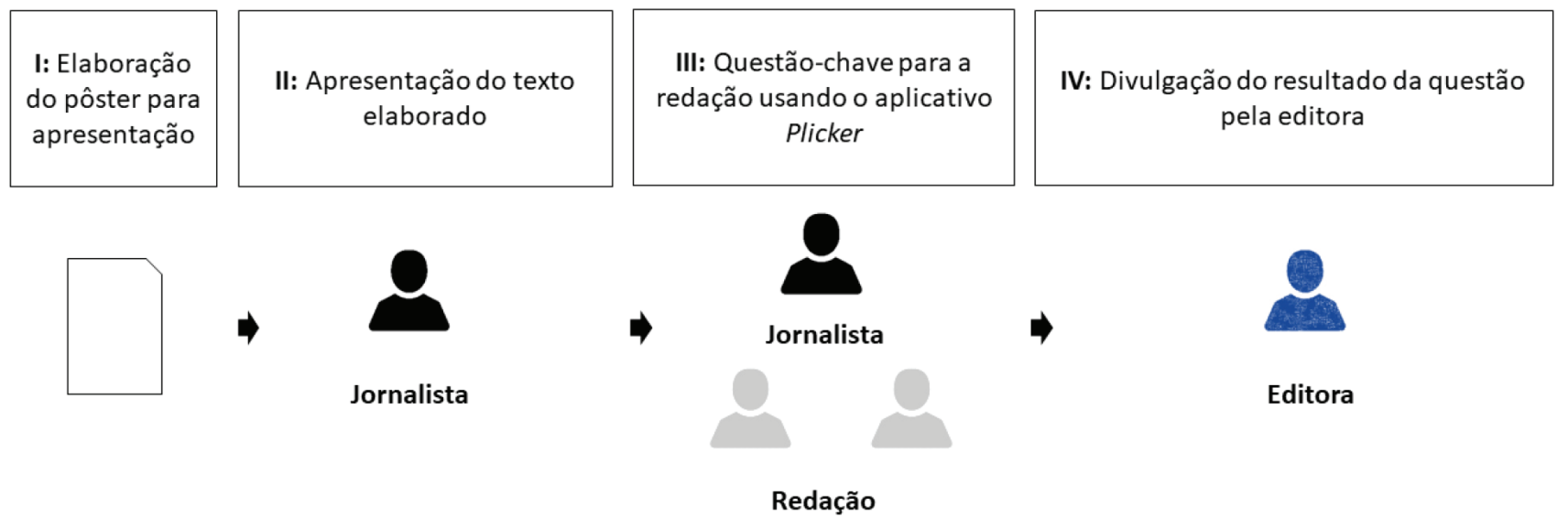

Figura 7. Simulação da redação de uma revista de ciência na etapa de apresentação dos TDC, pautada em AC

instantaneamente divulgado por parte da ministrante, no papel de editora.

Após essa rodada de apresentações orais intercaladas por suas questões-chave, a editora entregou a ficha de análise dos TDC produzidos para cada um de seus autores (preenchida após o recebimento das mesmas na etapa anterior), com comentários referentes aos elementos encontrados no TDC de autoria dos graduandos e a correspondência com os elementos estudados durante o curso. Na sequência, realizou-se uma roda de conversa sobre os temas abordados e a necessidade de se prosseguir com a CPC. Os participantes responderam à questão $O$ que você entende por comunicação pública de ciência?, preencheram formulário de feedback do curso e autoavaliação com uso de escala Likert e questões dissertativas.

\section{CONHECIMENTOS SOBRE CPC DE GRADUANDOS EM QUÍMICA}

Os conhecimentos de CPC dos graduandos em química foram investigados sob duas perspectivas. A primeira diz respeito ao conjunto de informações que já dispunham com relação aos veículos de divulgação científica, antes do início do curso, enquanto a segunda está associada aos conhecimentos que mobilizaram na produção de TDC e às facilidades e dificuldades que enfrentaram para tanto, na etapa final do curso.

\section{Conhecimentos sobre veículos de divulgação científica}

Com o intuito de averiguar o entendimento dos estudantes do que seria um TDC e conhecer os veículos de divulgação científica que lhes eram familiares, foi solicitado que respondessem duas perguntas, discutidas a seguir.

A primeira pergunta, Qual das alternativas abaixo é um veículo com Textos de Divulgação Científica para um público amplo?, com quatro alternativas, alcançou os seguintes percentuais de resposta: Superinteressante $(83,3 \%)$; Uma breve história do tempo - Stephen Hawking (16,6\%); Princípios de Química - Atkins \& Jones (0,0\%); Journal of Chemical Education (0,0\%).

Os resultados mostraram que a revista Superinteressante foi indicada como resposta correta pela grande maioria dos estudantes, enquanto uma parcela significativamente menor identificou o livro "Uma breve história do tempo" como um veículo de TDC.

Ambas são produções textuais com finalidade de divulgação científica, que corroboram com os elementos propostos no Quadro Analítico de $\mathrm{TDC}^{14}$ de apresentar recursos como linguagem acessível a um público leigo, título atrativo, explicação de conceitos por intermédio de recursos de linguagem, aspectos históricos da ciência, entre outros. Porém, o livro trata de uma única narrativa, melhor compreendido como um texto literário de divulgação científica (TLDC), ${ }^{19}$ enquanto que a revista Superinteressante é um veículo no qual estão compilados diversos TDC, constituindo-se assim a resposta esperada à pergunta proposta.

Mesmo assim, as respostas escolhidas mostraram um entendimento comum e adequado de divulgação científica pelos estudantes, frente às outras alternativas não selecionadas, que consistiam em um livro didático e em um veículo de relatos de experiência e de artigos originais de pesquisa da área de educação em química.

A segunda pergunta, Com quais desses veículos de divulgação científica você já teve contato?, com onze alternativas, alcançou os seguintes percentuais de resposta, conforme ilustra a Figura 8: Manual do Mundo (100,0\%); Superinteressante (83,3\%); Pesquisa FAPESP (66,7\%); Ciência Hoje (50,0\%); Nerdologia (33,3\%); Royal Society of Chemistry Experiments (33,3\%); Canadian Space Agency - Chris Hadfield (33,3\%); Galileu (16,7\%): WIRED (16,7\%); ACS Reactions (16,7\%); Scientific American (16,7\%).

Os veículos, com produções em diferentes formatos, incluem blogs, vídeos, revistas com corpo editorial especializado, podcasts e infográficos.

Os resultados ilustrados na Figura 8 mostram que, dentre os veículos de divulgação científica com os quais os participantes tiveram contato, destacam-se aqueles em língua portuguesa, liderados por um meio de comunicação no formato de blog, o Manual do Mundo. Na sequência, estão as revistas Superinteressante, Pesquisa FAPESP e Ciência Hoje. Em contraponto, grande parte das alternativas menos assinaladas remetem a produções em língua inglesa, independente do formato adotado. O inglês como língua franca para comunicação da ciência, embora global, não é de todo inclusivo, principalmente considerando o panorama histórico do aprendizado do idioma ao longo do currículo escolar ${ }^{20,21}$ e a confiança dos brasileiros no exercício do idioma estrangeiro, ${ }^{22}$ o que pode ter sido um potencial influenciador no conhecimento sobre veículos de divulgação científica dos participantes.

$\mathrm{O}$ acesso facilitado à Internet provavelmente também interviu no menor ou maior conhecimento dos estudantes a respeito de determinados veículos identificados. Ainda, a participação como colaboradores do grupo de extensão American Chemical Socitey Student Chapter do IQSC faz com que os estudantes trabalhem regularmente com apresentações lúdicas de ciência por meio de demonstrações experimentais em química, o que explica a seleção do veículo indicado em maior proporção: o conteúdo disponível no canal Manual do Mundo. ${ }^{23}$ Ele traz em seu cerne várias produções a respeito de experiências científicas. 




Percentual dos estudantes que relataram acesso ao veículo

Figura 8. Resposta percentual do número de estudantes que relataram ter acesso prévio aos veículos de divulgação científica descritos

\section{Conhecimentos mobilizados na produção de textos de divulgação científica}

Conforme mencionado anteriormente, cada um dos estudantes redigiu um TDC de tema livre ao final do curso. Para investigar os conhecimentos mobilizados por eles para o cumprimento da empreitada $\mathrm{e}$, consequentemente especular a respeito das facilidades e dificuldades com as quais se depararam, as seis produções textuais foram analisadas com base nos elementos propostos no Quadro Analítico. ${ }^{14}$ Estas são assim intituladas: A ciência desbravando o cosmos (1); De onde vêm os raios cósmicos? (2); Produção de corantes alimentícios por microrganismos (3); Neurônios sensitivos criados em laboratório podem evitar o uso de animais (4); A ascensão dos fracos e a queda dos gigantes: a luta pela sobrevivência na Mata Atlântica (5); e O vírus Zika como um aliado contra tumores (6).

A análise será apresentada em dois blocos, Conteúdo e Forma, conforme ilustra a Figura 1.

\section{Conteúdo dos TDC produzidos no curso de CPC}

No bloco vinculado ao Conteúdo, considera-se a Análise Geral e Específica. A Análise Geral indicou que os conteúdos dos TDC se caracterizaram majoritariamente como sendo de Fronteiras e Transversais. Os TDC (1) e (2), por exemplo, encaixam-se na primeira definição pois abordaram tópicos relacionados à astronomia, e o mesmo ocorre com os TDC (3), (4) e (6), no que diz respeito à biologia. O TDC (5) encaixa-se na segunda definição pois lida com noções de cidadania e sustentabilidade.

A Análise Específica indicou que Temáticas variadas foram escolhidas pelos estudantes: o TDC (1) tratou de fenômenos de radiação que são diretamente relacionados ao surgimento de buracos negros; o (2) abordou definições e origens dos raios cósmicos; o (3) discorreu sobre as vantagens e motivos para desenvolver corantes alimentícios a partir de microrganismos; o (4) teve como enfoque os novos recursos para pesquisas a fim de evitar testes em animais; o (5) traz em seu cerne um discurso de conscientização ambiental a respeito da fauna brasileira e os desequilíbrios que ela sofre por diversas causas; e o (6) tratou da aplicação de um patógeno com ação no combate a células tumorosas. As escolhas e desenvolvimentos das temáticas mostraram-se, em maior ou menor extensão, alinhadas com conhecimentos discutidos no curso. De fato, nos TDC (1) e (2), por exemplo, constata-se o potencial do assunto em despertar interesse, uma vez que o céu fascina o homem a milhares de anos, sendo a astronomia considerada a mais antiga das ciências. ${ }^{24}$ Ademais, este é apresentado em tom de impacto: "A ciência desbravando o cosmos" e "De onde vêm os raios cósmicos?". Em contraponto, a tarefa de contextualizá-lo para o leitor de forma acessível mostrou-se complexa para os estudantes, uma vez que as novidades sobre as quais se propuseram a tratar eram de aporte teórico e com o caráter de cooperação com o desenvolvimento da ciência por meio da construção de um novo conhecimento. Esse caráter é evidenciado usualmente em pesquisas de base, segundo a National Science Foundation. ${ }^{25}$

Com relação aos TDC (3) e (4), estes destacaram-se pela facilidade de identificação do leitor com os temas, uma vez que os assuntos corantes e alimentos são próximos ao cotidiano da maioria das pessoas, e a questão polêmica do uso de animais em pesquisas encontra-se atualmente muito em voga. O TDC (5) carregou um tom de impacto e proximidade com o leitor, uma vez que o Brasil é um país com enorme biodiversidade. ${ }^{26}$ Ao mesmo tempo, o assunto mostrou-se desafiador para o estudante, pois a contextualização sobre como determinados fenômenos isolados em regiões do Brasil podem impactar a população de áreas afastadas se fez necessária, a fim de conectar o assunto à realidade de um leitor que se situasse fora da área em foco no texto, que era a Mata Atlântica.

O TDC (6) tratou de uma questão aparentemente controversa e de aplicações na área da saúde a respeito de doença Zika, já considerada epidêmica no cenário brasileiro. No entanto, o seu entendimento requeria a inserção de conceitos de virologia e biologia molecular, não triviais aos leitores.

A abordagem das referidas Temáticas em todos os TDC foi perpassada pela apresentação de Características da Atividade Científica. Ou seja, os estudantes, novamente, mobilizaram conhecimentos que haviam sido discutidos ao longo do curso, voltados ao entendimento das mesmas. Nessa perspectiva, para cada uma das Características identificadas (itens a - h) está associado, na sequência, um excerto extraído dos TDC de autoria dos estudantes. Cabe destacar a existência de outros excertos nos TDC que também se remetiam às mesmas Características, mas que não foram aqui elencados com o propósito de não comprometer a fluidez da leitura do presente texto.

(a) descrição de metodologias: TDC (3) "Os pigmentos são obtidos pela filtração do micélio - "corpo" do microorganismo - que é então triturado para extração dos pigmentos em solventes orgânicos não tóxicos";

(b) conclusões de análises/pesquisas: TDC (1) "O novo estudo sobre buracos negros primordiais ajuda a estabelecer conexões entre a teoria e as observações";

(c) aplicações: TDC (3) "Dentre os vários produtos que podem ser obtidos por meios biotecnológicos, a produção de pigmentos microbianos tem sido cada vez mais procurada como alternativa para obtenção de corantes alimentícios";

(d) trabalho em equipe/cooperação entre grupos de pesquisa: TDC (4) "Alguns pesquisadores do Instituto de Ciências Biomédicas da Universidade Federal do Rio de Janeiro (UFRJ) e do Instituto 
D’Or de Pesquisa e Ensino criaram em seus laboratórios, com êxito, neurônios sensitivos";

(e) interpretação de resultados: TDC (2) "Mas os estudos indicaram que eles estavam percorrendo um caminho bem distante do centro da galáxia, o que comprova o fato de que esses raios vêm de outras galáxias vizinhas à nossa";

(f) menção ao prêmio Nobel: TDC (2) "Quando o físico trabalhava junto a Jim Cronin, vencedor do Prêmio Nobel em 1980";

(g) formulação de hipótese: TDC (4) "E quem sabe, no futuro, gerar um órgão humano completo";

(h) presença de controvérsia científica (6) "Apesar dos efeitos catastróficos da epidemia pelo vírus Zika sobre a saúde de recém-nascidos, seria possível utilizar os efeitos lesivos deste parasita para o nosso benefício?".

A apresentação de várias Características da Atividade Científica ao longo de todos os TDC produzidos indica a facilidade dos autores na inclusão das mesmas. Por outro lado, chamou a atenção a ausência da descrição metodológica no TDC (4), culminando em uma quebra de expectativa na leitura, uma vez que a temática propaga uma inovação conquistada por via sintética, mas não a descreve ao longo do texto.

A Análise Específica também indicou que as Abordagens $e$ Contextos predominantes nos TDC produzidos foram a científica, tecnológica e conceitual, seguida da ambiental em menor proporção. Os TDC considerados com abordagem científica foram (1), (2) (3), (4) e (6), pois abarcaram questões inerentes às dificuldades e facilidades do processo de construção da ciência, e suas respectivas características. Os TDC considerados com abordagem tecnológica foram o (3), (4) e (6), uma vez que enfatizaram o potencial das aplicações dos temas tratados, no caso, respectivamente, o potencial de aplicação de pigmentos microbianos como alternativa para a obtenção de corantes alimentícios, o desenvolvimento de neurônios sensitivos para evitar o uso de animais em testes de medicamentos e a capacidade do vírus Zika em destruir células tumorais.

Os TDC (1) e (2) foram considerados como sendo de abordagem conceitual, pois trazem de forma recorrente parágrafos intercalados com procedimentos explicativos sobre o tema ao qual se dedicam, para melhor entendimento do texto, conforme ilustra o excerto a seguir, extraído do TDC (2): "por raios cósmicos entende-se por partículas extremamente penetrantes (pequena concentração de massa capaz de penetrar, por exemplo, na atmosfera) que possuem altíssima energia, chegando a ser milhões de vezes mais energéticos que partículas geradas em aceleradores". Nos dois casos, os TDC trataram de novos conhecimentos e do caráter teórico dos mesmos.

O TDC de conteúdo predominantemente ambiental, por sua vez, foi o (6), que apresentou uma mensagem de conscientização sobre o assunto, conforme indica o excerto a seguir, que finaliza o texto: "A conscientização é necessária para prevenir esses casos e apesar de dificilmente ser possível reverter essa situação, ainda é possível desacelerar esse processo e inúmeros outros que ocorrem graças à má influência do homem. Com isso, pergunte a si mesmo e ao próximo, o que posso fazer para mudar isso?".

As distintas abordagens e contextos observados corroboram com a natureza do discurso de divulgação nos textos produzidos, refletindo os aspectos de cientificidade, laicidade e didaticidade dos mesmos. ${ }^{27}$ Isso é, trechos da escrita que rementem a características implícitas e/ou explícitas da atividade científica, do cotidiano e de recursos didáticos como conceituações e metodologias, ${ }^{28}$ por exemplo.

\section{Forma dos TDC produzidos no curso de CPC}

No bloco vinculado à Forma, considera-se a Estrutura, Linguagem e Recursos Visuais e Textuais. Com relação à Forma, esperava-se identificar características estruturais propostas no Quadro Analítico $^{14}$ nos TDC produzidos, incluindo a redação do texto em uma sequência lógica, com ou sem fragmentações, uso de lides e/ou boxes e a presença, ou não, de tópicos (independentes ou dependentes entre si). Sobre tal, apenas o TDC (6) apresentou o texto em duas colunas, ao passo que os demais produziram textos corridos. Além disso, nenhum TDC se utilizou de subtítulos e subtópicos. Ou seja, recursos que incrementariam a Forma de apresentação dos TDC, como os citados anteriormente, não foram empregados por grande parte dos estudantes, indicando uma dificuldade a ser superada por eles na produção de textos dessa natureza.

A Linguagem empregada em todos os TDC foi ao encontro das recomendações a esse respeito oferecidas durante o curso. De fato, vários recursos estiveram presentes nos textos, conforme ilustrado a seguir. Para cada um dos recursos de Linguagem identificados (itens a - f) está associado, na sequência, um excerto extraído dos TDC de autoria dos estudantes. Cabe destacar a existência de outros excertos nos TDC que também se remetiam aos mesmos recursos de Linguagem, mas que não foram aqui elencados com o propósito de não comprometer a fluidez da leitura do presente texto.

(a) definição por conceituação: TDC (6) "Na escola aprendemos que todos os organismos vivos são compostos desde pelo menos uma célula (espécies unicelulares) ou até mesmo quantidades astronômicas de células (espécies pluricelulares)";

(b) comparações: TDC (1) "Essas radiações são ondas eletromagnéticas (que são semelhantes a ondas sonoras, mas que se propagam no vácuo do espaço) e apresentam padrão característicos para cada composto";

(c) busca de credibilidade (menção a instituições renomados na área): TDC (3) "No Brasil, desde 1999, a empresa Germinal e o Departamento de Engenharia Química da Escola Politécnica (Poli) da Universidade de São Paulo (USP) desenvolvem um processo de produção do pigmento vermelho";

(d) aspeamento (") com função de marcar o distanciamento relativo ao emprego de expressões que se originam em outras formações discursivas: TDC (1) "Mas diferentemente dos buracos negros, que são 'vistos' como a ausência de luz/radiação emitida";

(e) interpelação direta ao leitor: TDC (3) "Quantas vezes não ouvimos falar sobre o vírus da gripe, do HIV, da hepatite, ou quem nunca conheceu alguém que teve que ingerir uma batelada de antibióticos para se recuperar de uma infecção por bactéria?";

(f) aposto: TDC (1) "Aaron Smith, astrofísico do Instituto de Tecnologia de Massachusetts (Estados Unidos), justifica sucintamente o motivo dos estudos sobre buracos negros supermassivos".

A recorrência e diversidade de recursos de linguagem empregados pelos autores na redação dos TDC sugere a desenvoltura que apresentaram frente a esse aspecto abordado no curso.

Com relação aos Recursos Visuais e Textuais era esperado que os estudantes utilizassem imagens atraentes alusivas aos temas tratados e se valessem de artifícios que oferecessem destaque a títulos, subtítulos e retranca, por exemplo. Coerentemente, todos os estudantes anexaram imagens aos seus TDC, embora nenhuma delas tenha sido de autoria própria. Em uma perspectiva não esperada em textos desse naipe, o autor do TDC (2) ilustrou o mecanismo de um fenômeno conhecido como chuveiro atmosférico por meio de uma figura em tons de preto, branco e cinza, visualmente não atrativa. Além disso, destaques a títulos, subtítulos e retrancas não foram feitos por nenhum dos estudantes.

Assim como observado com relação à Forma de apresentação dos TDC, o uso de Recursos Visuais e Textuais limitados e até mesmo equivocados sugere ser essa outra dificuldade a ser superada pelos estudantes na elaboração de TDC.

\section{CONSIDERAÇÕES FINAIS}

É inegável a imbricação entre ciência e sociedade, existindo, 
segundo Castells, ${ }^{29}$ um processo de realimentação entre elas. Nessa perspectiva, quando os cientistas comunicam ao público os resultados das pesquisas que desenvolvem, propiciam aos cidadãos ferramentas para construção de opiniões próprias, com base em dados e fatos respaldados pela comunidade à qual pertencem. No entanto, a comunicação só ocorre de forma profícua se alcança a população de modo que a entenda e dela tire proveito. Para alcançar tal patamar, é consensual a ideia de que os cursos superiores da área de ciências naturais necessitam desencadear ações que conduzam à formação de profissionais capazes de cumprir com esse propósito de comunicar ciência para o público em geral. . $^{30,31}$

Dessa forma, é pertinente encarar a escrita e divulgação científica como um evento curricular, que deve ser abordado e praticado ao longo dos cursos de graduação nas referida área. ${ }^{8,9}$ Como essa não é uma empreitada fácil, iniciativas que envolvem o oferecimento de cursos e oficinas sobre a temática proliferam em vários países..$^{31-33}$ No Brasil, até onde vai o nosso conhecimento, relatos a respeito de oferecimentos dessa natureza, voltados especificamente para graduandos em química, são ainda pouco recorrentes. É nesse contexto que o presente manuscrito ganha relevância, trazendo contribuições para que sejam ampliadas tais iniciativas. A tessitura das seguintes considerações oferece subsídios para tanto:

- A simulação de uma situação real, no caso a redação de uma revista de divulgação cientifica, permitiu que os estudantes, no papel de jornalistas, participassem de forma ativa e cooperativa de um processo que culminou na produção de um TDC, o que indica a relevância de pautar o oferecimento dos cursos de comunicação científica em estratégias promotoras de ações que propiciem participações desse tipo.

- A adequação do Quadro Analítico ${ }^{14}$ como ferramenta para apresentação aos estudantes dos elementos existentes em um TDC foi constatada, o que permite sugerir o seu uso em propostas didáticas futuras.

- Os conhecimentos exibidos pelos estudantes sobre veículos de divulgação científica apontam para a possibilidade de ampliação desse leque, a partir da consideração daqueles disponibilizados em idiomas estrangeiros.

- Na produção dos seus respectivos TDC os estudantes mobilizaram conhecimentos que se mostraram em sintonia com os tópicos abordados durante o curso de CPC, sugerindo a pertinência da discussão desses últimos.

- As facilidades e dificuldades dos estudantes na produção dos TDC, que foram constatadas e discutidas anteriormente, podem ser úteis na construção de novas propostas didáticas, uma vez que sinalizam aspectos a enfatizar para o alcance de resultados ainda mais promissores.

Ainda que a proposta do presente estudo se apresente no contexto de um curso de curta duração foi percebida a dificuldade dos alunos em contextualizar um fato científico, indicando aspectos que devem ser discutidos ao longo do ensino superior, a fim de que esse se aproxime de uma formação de excelência, tanto no que diz respeito aos conhecimentos técnicos quanto humanísticos que subsidiam a intrínseca relação entre Ciência, Tecnologia e Sociedade e fundamentam o princípio da indissociabilidade entre a Pesquisa, o Ensino e a Extensão, pilares sobre os quais as universidades são estruturadas. ${ }^{34}$ Por fim, espera-se que a experiência aqui relatada seja capaz de fornecer elementos que contribuam na formação de graduandos em química comprometidos com a democratização e popularização da ciência.

\section{AGRADECIMENTOS}

O presente trabalho foi realizado com apoio do grupo de extensão
American Chemical Society University of São Paulo Student Chapter do IQSC/USP e do CDCC/USP.

\section{REFERÊNCIAS}

1. Lewenstein, B. V.; ArtefaCTos 2010, 3, 1.

2. Murcott, T. H. L.; Nature 2009, 459, 1054.

3. Rensberger, B.; Nature 2009, 459, 1055.

4. Weigold, M. F.; Sci. Commun. 2001, 23, 2.

5. https://opiniao.estadao.com.br/noticias/geral,excelencia-academicarequer-custeio-publico,70002139008, acessada em junho 2020.

6. https://www.topuniversities.com/university-rankings/world-universityrankings/2020, acessada em junho 2020.

7. Treise, D.; Weigold, M. F.; Sci. Commun. 2002, 23, 3.

8. Sotério, C.; Silva, G. B.; Queiroz, S. L.; Anais XVII EVEQ - Evento de Educação em Química, Araraquara, Brasil, 2019.

9. Zucco, C.; Pessine, F. B. T.; Andrade, J. B.; Quim. Nova 1999, 22, 3

10. Oliveira, J. R. S.; Queiroz, S. L.; Quim. Nova 2015, 38, 4.

11. Johnson, D. W.; Johnson, R. T.; Holubec, E. J.; Cooperative learning in the classroom, The Association for Supervision and Curriculum Development:Virginia, 1994.

12. Teodoro, D. L.; Silva, G. B.; Queiroz, S. L.; Investigações em Ensino de Ciências 2019, 24, 3 .

13. Jinu, R.; Beegum, S. S.; International Journal of Recent Technology and Engineering 2019, 8, $2 \mathrm{~S} 3$.

14. Ferreira, L. N. A.; Queiroz, S. L.; Quim. Nova 2011, 34, 2.

15. http://basenacionalcomum.mec.gov.br/images/BNCC_EI_EF_110518_ versaofinal_site.pdf, acessada em junho 2020.

16. Oliveira, J. R. S.; Queiroz, S. L.; Comunicação e Linguagem Científica: guia para estudantes de química, Editora Átomo: Campinas, 2017.

17. https://revistapesquisa.fapesp.br/2014/10/09/luz-que-enxerga-o-que-naoviu, acessada em junho 2020.

18. Cabral, P. F. O.; Peron, K. A.; Queiroz, S. L.; Quim. Nova 2019, 42, 2.

19. Targino, A. R. L.; Giordan, M.; Anais do XVIII Encontro Nacional de Ensino de Química (ENEQ), Florianópolis, Brasil, 2016.

20. britishcouncil.org.br/sites/default/files/estudo_ oensinodeinglesnaeducacaopublicabrasileira.pdf, acessada em junho 2020.

21. Bordini, M.; Gimenez, T.; Signum: Estudos da Linguagem 2014, 17, 10.

22. Carreão, V.; Revista Desafios 2017, 4, 3.

23. https://www.youtube.com/channel/UCKHhA5hN2UohhFDfNXB_cvQ, acessada em junho 2020.

24. Júnior, E. C.; Fernandes, B. S.; Lima, G. S.; Siqueira, A. J.; Paiva, J. N. M.; Santos, M. G.; Tavares, J. P.; Souza, T. V.; Gomes, T. M. F.; Rev. Bras. Ensino Fis. 2018, 40, 4.

25. https://www.nsf.gov/pubs/1953/annualreports/ar_1953.pdf, acessada em junho 2020.

26. Alho, C. J. R.; Estudos avançados 2012, 26, 74.

27. Zamboni, L. M. S.; Tese de doutorado, Universidade Estadual de Campinas, Brasil, 1997.

28. Ferreira, L. N. A.; Queiroz, S. L.; Revista Electrónica de Enseñanza de las Ciências 2012, 11, 1.

29. Castells, M.; A sociedade em rede, Paz e Terra: São Paulo, 1999.

30. Jucan M. S.; Jucan, C. N.; Procedia - Social and Behavioral Sciences 2014, 149, 461.

31. https://www.isa.ulisboa.pt/ensino/outros-cursos/cccpg, acessada em junho 2020.

32. https://www.uio.no/studier/emner/matnat/ibv/MNKOM9010/index.html, acessada em junho 2020.

33. https://sites.duke.edu/environ798_01_s2014/files/2014/01/ENVIRON798-1-syllabus-Spring-2014.pdf, acessada em junho 2020.

34. https://www.senado.leg.br/atividade/const/con $1988 /$ con1988_18.02.2016/art_207_.asp, acessada em junho 2020. 